\title{
Uptake of Tyrosine Amino Acid on Nano-Graphene Oxide
}

\author{
Hossam M. Nassef ${ }^{1,2}$, Mohamed Hagar ${ }^{1,3}$, Zeiad Malek ${ }^{1}$ and Abdelhameed M. Othman ${ }^{1,4, *}$ \\ 1 Chemistry Department, Faculty of Science at Yanbu, Taibah University, Yanbu 46423, Saudi Arabia; \\ hossamnassef2002@gmail.com (H.M.N.); mohamedhaggar@gmail.com (M.H.); \\ waleed2993@gmail.com (Z.M.) \\ 2 Chemistry Department, Faculty of Science, Damietta University, Damietta 34517, Egypt \\ 3 Chemistry Department, Faculty of Science, Alexandria University, Alexandria 23132, Egypt \\ 4 Environmental Biotechnology Department, Genetic Engineering and Biotechnology Research Institute, \\ University of Sadat City, Sadat City 32897, Egypt \\ * Correspondence: ayosefaly@taibahu.edu.sa; Tel.: +966-540-673-967
}

Received: 3 December 2017; Accepted: 29 December 2017; Published: 4 January 2018

\begin{abstract}
Graphene oxide (GO) is emerging as a promising nanomaterial with potential application in the detection and analysis of amino acids, DNA, enzymes, and proteins in biological fluid samples. So, the reaction of GO with amino acids should be characterized and determined before using it in biosensing methods and devices. In this study, the reaction of tyrosine amino acid (Tyr) with GO was characterized using FT-IR, UV-vis spectrophotometry, and scanning electron microscopy (SEM) before its use. The optimum conditions for GO's interaction with Tyr amino acid have been studied under variable conditions. The optimum conditions of $\mathrm{pH}$, temperature, shaking time, and GO and tyrosine concentrations for the uptaking of tyrosine amino acid onto the GO's surface from aqueous solution were determined. The SEM analysis showed that the GO supplied was in a particle size range between 5.4 and $8.1 \mathrm{~nm}$. A pH of $8.4-9.4$ at $25^{\circ} \mathrm{C}$ and $5 \mathrm{~min}$ of shaking time were the optimum conditions for a maximum uptake of $1.4 \mu \mathrm{g} / \mathrm{mL}$ of tyrosine amino acid onto $0.2 \mathrm{mg} / \mathrm{mL}$ of GO.
\end{abstract}

Keywords: graphene oxide; amino acid; tyrosine; uptaking; SEM

\section{Introduction}

Graphene oxide (GO) is a novel single-atom-thick and two-dimensional carbon material produced by the oxidation of graphite that contains oxygen functional groups, such as epoxides, phenol hydroxyls, and carboxylic groups [1-3]. The oxygenated lattice of GO not only facilitates better water solubility and stability, but allows for noncovalent interaction with diols, amine functional groups, and phenyls in biomolecules through electrostatic interaction, $\pi-\pi$ stacking, and hydrogen bonding to enable the recognition of biomolecules with detectable specificity [4]. Recently, GO has attracted considerable attention due to its extraordinary electronic, optical, and thermal properties in comparison to other nanomaterials. The superior characteristics of GO, such as its large surface area, good water dispersibility and biocompatibility, facile surface modification, and low manufacturing cost, make it a promising material for biotechnology and biosensing applications [5-8]. GO has been shown to quench organic fluorescence molecules due to long-range nano-scale energy transfer [9].

Recent experimental results indicate that some amino acids, peptides, and proteins can be quickly adsorbed onto the surface of $\mathrm{GO}$ because of electrostatic interaction, hydrophobic interaction, and hydrogen bonding [10]. Amino acids are molecules containing at least one amino group, a carboxylic group, and a side chain that varies between different amino acids. Amino acids are important to life and have many functions in metabolism; one particularly important function is to serve as the building blocks of proteins. Many proteins have residual amino acids in their structure, such as tryptophan and tyrosine (Tyr), and due to their central role in biochemistry, amino acids are important in nutrition 
and are commonly used in food technology and industry. Tyrosine and Tryptophan are two amino acids that contribute to our emotional well-being and mental alertness as well as participate in a wide variety of other healthful benefits [11]. Amino acids appear as promising molecules to be immobilized on nanomaterials [12-14]. One of the recent studies in this area used GO as an optical sensor for the determination of the L-tryptophan amino acid (Trp) in the presence of other amino acids, such as L-asparagine, L-histidine, L-phenylalanine, L-arginine, L-tyrosine, L-lysine, L-ascorbic acid, tartaric acid and uric acid, by a spectrofluorometric method [15]. The chemical composition of GO is not yet fully known, and due to the high reactivity of the oxygenated groups, mainly the epoxy, hydroxyl, and carboxyl groups, several derivatization reactions may occur at the same time [16]. In this study, graphene oxide was used as an absorbing material for tyrosine amino acids in aqueous solution. Different parameters were tested to determine the optimum conditions for the uptaking of tyrosine amino acid, such as $\mathrm{pH}$, temperature, $\mathrm{GO}$ and tyrosine concentration, and shaking time. These data showed that the uptake of tyrosine amino acid on the surface of GO can serve as a technique for the separation and determination of amino acids or protein with residual tyrosine amino acid from aqueous and biological fluids.

\section{Experimental}

\subsection{Material and Instruments}

Graphene oxide was obtained from Advanced Chemical Supplier ACS Material LLC., Pasadena, CA, USA. The particle size of the GO was determined by Scanning Electron Microscopy (SEM-FEI, FEG Quants 250, Hillsboro, OR, USA, magnification 20-1,000,000 $\times$ high resolution). All spectrophotometric measurements were carried out at $25 \pm 1{ }^{\circ} \mathrm{C}$ using a UV-vis spectrophotometer model (UV-1800 SHIMADZU, Nakagyo-KU, Kyoto, Japan). Fourier Transform Infrared Spectroscopy (FTIR) was carried out using a Nicolet iS 10 Thermo scientific (Waltham, MA, USA). A bench-top M545 meter was applied to adjust the $\mathrm{pH}$ (Pinnacle, Corning, NY, USA). A bench-top sonicator of Model 1510 was used to disperse graphene oxide in water and for the shaking time experiments (Branson, Danbury, CT, USA). The tyrosine amino acids were delivered from Sigma Co. (Munich, Germany).

\subsection{Methods}

\subsubsection{Particle Size Determination of GO}

The shape and size of the GO were studied by scanning electron microscopy (SEM-FEI, FEG Quants 250, Hillsboro, OR, USA, magnification 20-1,000,000 $\times$ high resolution).

\subsubsection{FT-IR of GO}

Fourier Transform Infrared Spectroscopy (FTIR) with a Nicolet iS 10 Thermo scientific (Waltham, MA, USA) was used to record and characterize the spectra of the GO before uptake within a scanning range of $400-4000 \mathrm{~cm}^{-1}$.

\subsubsection{UV-vis of GO}

UV-vis spectral data were measured on a spectrophotometer (UV-1800 SHIMADZU, Nakagyo-KU, Kyoto, Japan) in an aqueous solution of GO, Tyr, and GO-Tyr. The maximum absorption of wavelength was $279 \mathrm{~nm}$ for Tyr and $223 \mathrm{~nm}$ for GO, and the absorption spectra and area under peak were measured and calculated for different variables at $274 \mathrm{~nm}$.

\subsubsection{Effect of GO Concentration}

A stock solution of $1 \mathrm{mg} / \mathrm{mL}$ of $\mathrm{GO}$ aqueous dispersion was obtained by adding $50 \mathrm{~mL}$ of pure water to $50 \mathrm{mg}$ of GO, followed by sonication for $1 \mathrm{~h}$ in a cold water bath and dilution with pure water according to the needs of the experiment. Different concentrations $(0.1,0.2,0.3$, and $0.4 \mathrm{mg} / \mathrm{mL})$ of $\mathrm{GO}$ 
were prepared. One milliliter of each GO concentration was added to $4.0 \mathrm{~mL}$ of $1 \times 10^{-4} \mathrm{M}$ of Tyr, then the absorption spectra of Tyr-GO were recorded and the area under peak was calculated.

\subsubsection{Effect of $\mathrm{pH}$}

Measurements of the $\mathrm{pH}$ dependence of $4.0 \mathrm{~mL}$ of $1 \times 10^{-4} \mathrm{M}$ Tyr amino acid over $1 \mathrm{~mL}$ of GO $(1 \mathrm{mg} / \mathrm{mL})$ solution were performed over a wide range of $\mathrm{pH}(3-11)$. The $\mathrm{pH}$ was adjusted using dilute sodium hydroxide and/or hydrochloric acid, then the tested solution was completed to $5 \mathrm{~mL}$ with pure water. The absorption spectra and the area under peak were measured and calculated with different $\mathrm{pHs}$ at $274 \mathrm{~nm}$.

\subsubsection{Effect of Temperature}

The effect of temperature on the reaction of Tyr amino acid with GO was done by adding $4.0 \mathrm{~mL}$ of $1 \times 10^{-4} \mathrm{M}$ of Tyr amino acid solution to $1 \mathrm{~mL}$ of GO $(1 \mathrm{mg} / \mathrm{mL})$ solution and completing the solution to $5 \mathrm{~mL}$ by pure water. The absorption spectra and the area under peak were measured and calculated at different temperatures: $20,25,30,35$, and $40{ }^{\circ} \mathrm{C}$ at $274 \mathrm{~nm}$.

\subsubsection{Effect of Shaking Time}

The effect of time, with and without shaking, on the uptake of Tyr amino acid on the GO's surface has been investigated. Four milliliters of $1 \times 10^{-4} \mathrm{M}$ Tyr solution was added to $1 \mathrm{~mL}$ of GO solution $(1 \mathrm{mg} / \mathrm{mL})$. The absorption spectra were measured at $0.0,5,10,15,20$, and $25 \mathrm{~min}$ at $25 \pm 1^{\circ} \mathrm{C}$ and the area under peak at $274 \mathrm{~nm}$ was calculated.

\subsubsection{Uptake of Tyr Amino acid on GO}

To study the uptake of Tyr amino acid on the surface of GO, a solution of $4.0 \mathrm{~mL}$ of $1 \times 10^{-4} \mathrm{M}$ Tyr and $1 \mathrm{~mL}$ of GO $(1 \mathrm{mg} / \mathrm{mL})$ was prepared. The absorbance of the Tyr, GO, and Tyr/GO solutions was measured, and the areas under peak were calculated.

\section{Results and Discussion}

Using graphene oxide (GO) in biosensing and devices has recently been of significant interest in the biomedical field for the detection of specific biomolecules from body fluid samples [17-20]. GO has attracted considerable attention due to its extraordinary electronic, optical, and thermal properties in comparison to other nanomaterials. The superior characteristics of GO, such as its large surface area, good water dispersibility and biocompatibility, facile surface modification, and low manufacturing cost, make it a promising material for biotechnology and biosensing applications [21,22].

The reaction of GO with amino acids is interesting and has drawn attention in the last few years due to the high reactivity of the oxygenated moieties, mainly the epoxy, hydroxyl, and carboxyl groups [14].

The aim of our study is to characterize and determine the optimum conditions for the uptake of Tyr amino acid onto the surface of GO.

\subsection{Characterization of $G O$}

A commercially available GO, used in this study, was not synthesized in our lab. It was purchased from Advanced Chemical Supplier (ACS) Material LLC (Medford, MA, USA), and has been fully characterized by the company [23] (supplementary data, Figures S1-S6).

\subsubsection{FT-IR of GO}

The FT-IR of GO (Figure 1) showed a strong peak at $1715 \mathrm{~cm}^{-1}$ assigned to $\mathrm{C}=\mathrm{O}$ (carbonyl/carboxy), while the peak at $1614 \mathrm{~cm}^{-1}$ was attributed to $\mathrm{C}=\mathrm{C}$ (aromatics), the peak at 
$1437 \mathrm{~cm}^{-1} \mathrm{C}-\mathrm{O}$ (carboxy), the peak at $1241 \mathrm{~cm}^{-1} \mathrm{C}-\mathrm{O}$ (epoxy), and the peak at $1038 \mathrm{~cm}^{-1} \mathrm{C}-\mathrm{O}$ (alkoxy). These data are consistent with previously reported studies [17-20,22].

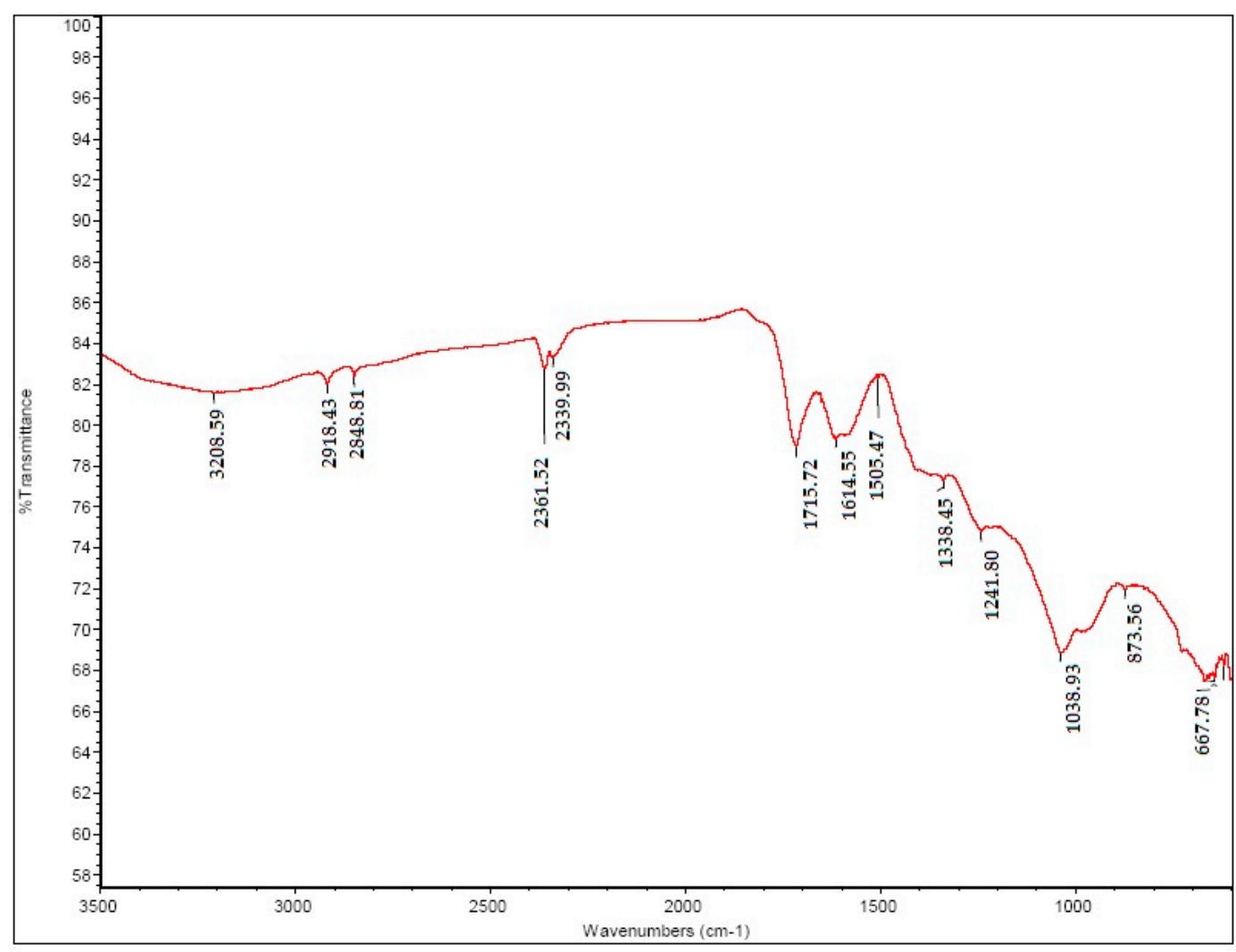

Figure 1. FT-IR of graphene oxide (GO).

\subsubsection{UV-vis of GO}

The UV-vis spectra of GO are shown in Figure 2. They exhibit a maximum absorption peak at about $223 \mathrm{~nm}$, corresponding to the $\pi-\pi^{*}$ transition of aromatic $\mathrm{C}-\mathrm{C}$ bonds.

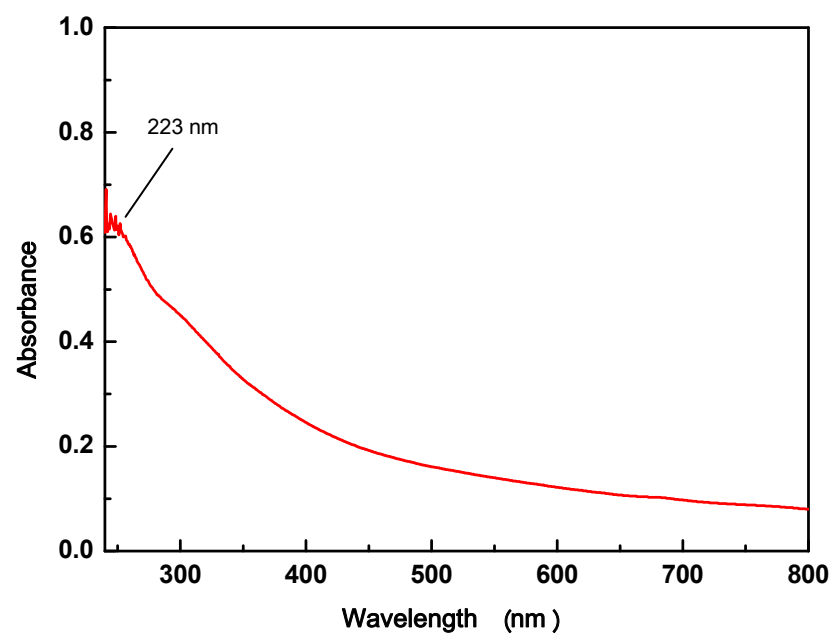

Figure 2. UV-vis of GO. 


\subsubsection{SEM of GO}

Morphological studies of the GO were performed by SEM. The SEM micrographs are shown in Figure 3. It can be observed that the matrix of GO is clear and that the particle size is in the range of 5.4 to $8.1 \mathrm{~nm}$. The particles are regular in shape and not variable in size.

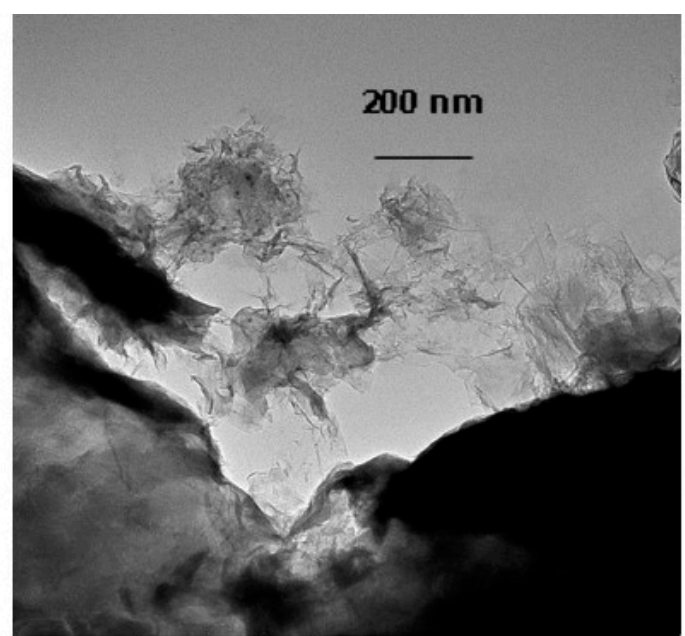

Mic IEM-1400 $100000 \times 90 \mathrm{kV} \mid \mathrm{Go}-\mathrm{g}$
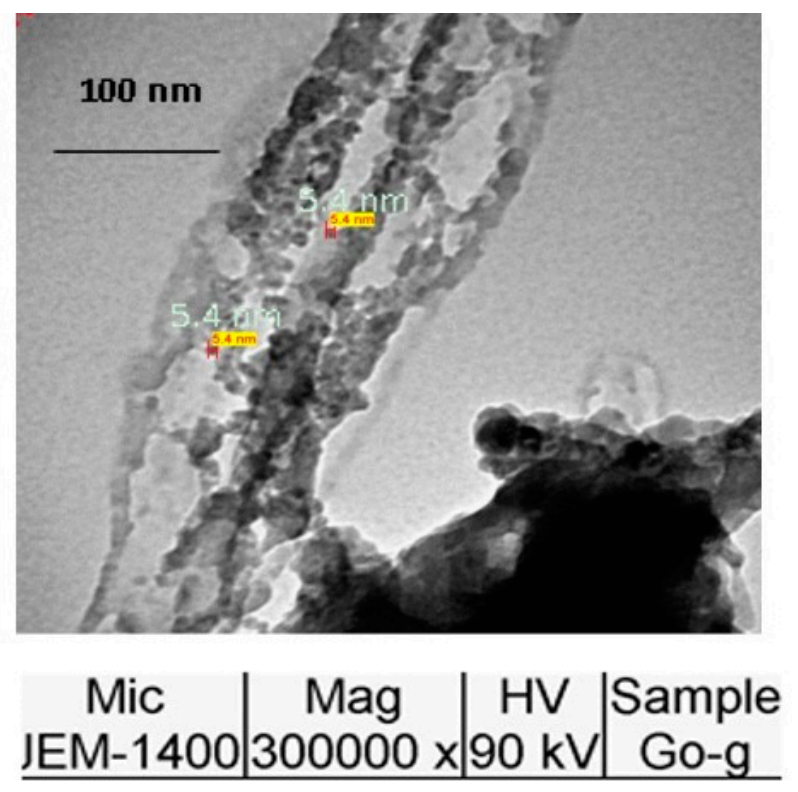

Figure 3. SEM analysis of GO.

\subsection{Effect of $G O$ Concentration}

The uptake of Tyr in the presence of different concentrations $(0.05,0.1,0.2,0.3$, and $0.4 \mathrm{mg} / \mathrm{mL})$ of GO is shown in Figure 4. The calculated data of the corresponding peak area showed that the minimum concentration of GO used for the maximum uptake of Tyr amino acid was $0.2 \mathrm{mg} / \mathrm{mL}$. So, this concentration was used in the subsequent experiments.

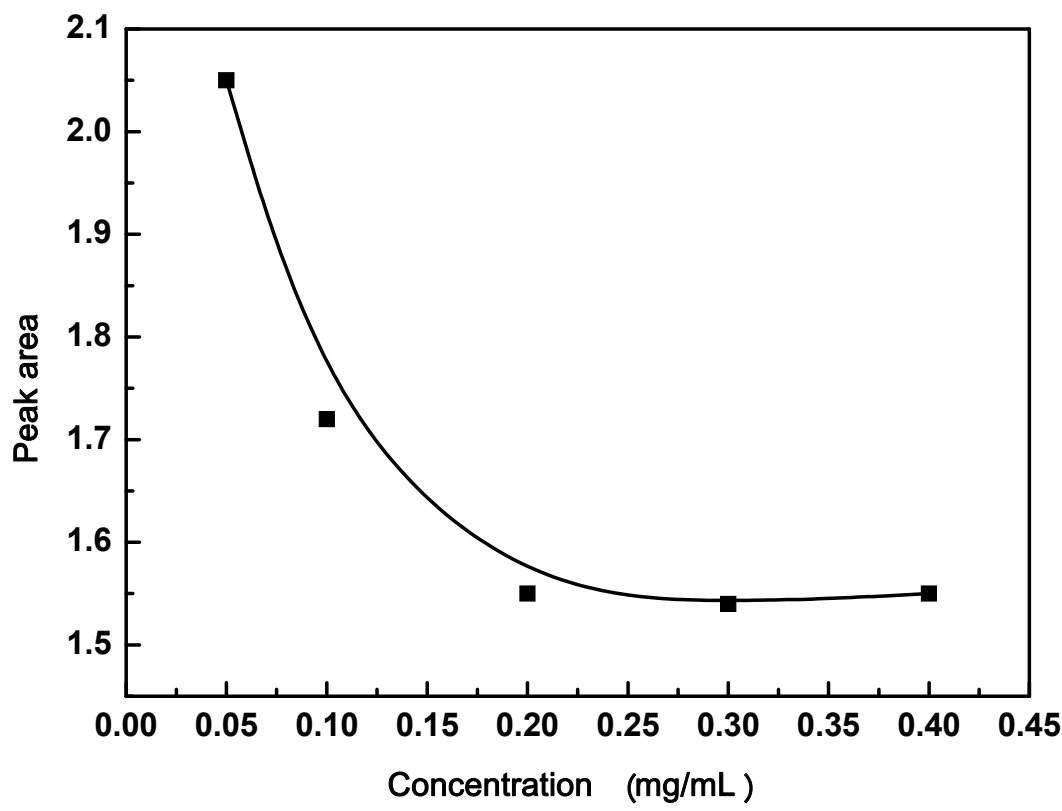

Figure 4. The influence of GO concentration on the adsorption of tyrosine (Tyr) amino acid. 


\subsection{Effect of $p H$}

Different pHs of Tyr-GO solutions (3.0, 4.7, 6.9, 7.6, 8.6, 9.4, and 11.0) were prepared, and the absorption spectra and the area under peak were calculated to determine the optimum $\mathrm{pH}$ for the adsorption of Tyr onto GO. The obtained data (Figure 5) showed that the smallest area under peak was found at a pH between 8.4 and 9.4. These data indicate that the interaction between Tyr and GO was increased when increasing the $\mathrm{pH}$ up to $\mathrm{pH}$ 8.6, then the peak area returned to an increase. This adsorption behavior of Tyr is mainly due to an electrostatic attraction to GO, so as the $\mathrm{pH}$ increases, the negative charge on Tyr increases and consequently the uptake of Tyr on the GO's surface decreases.

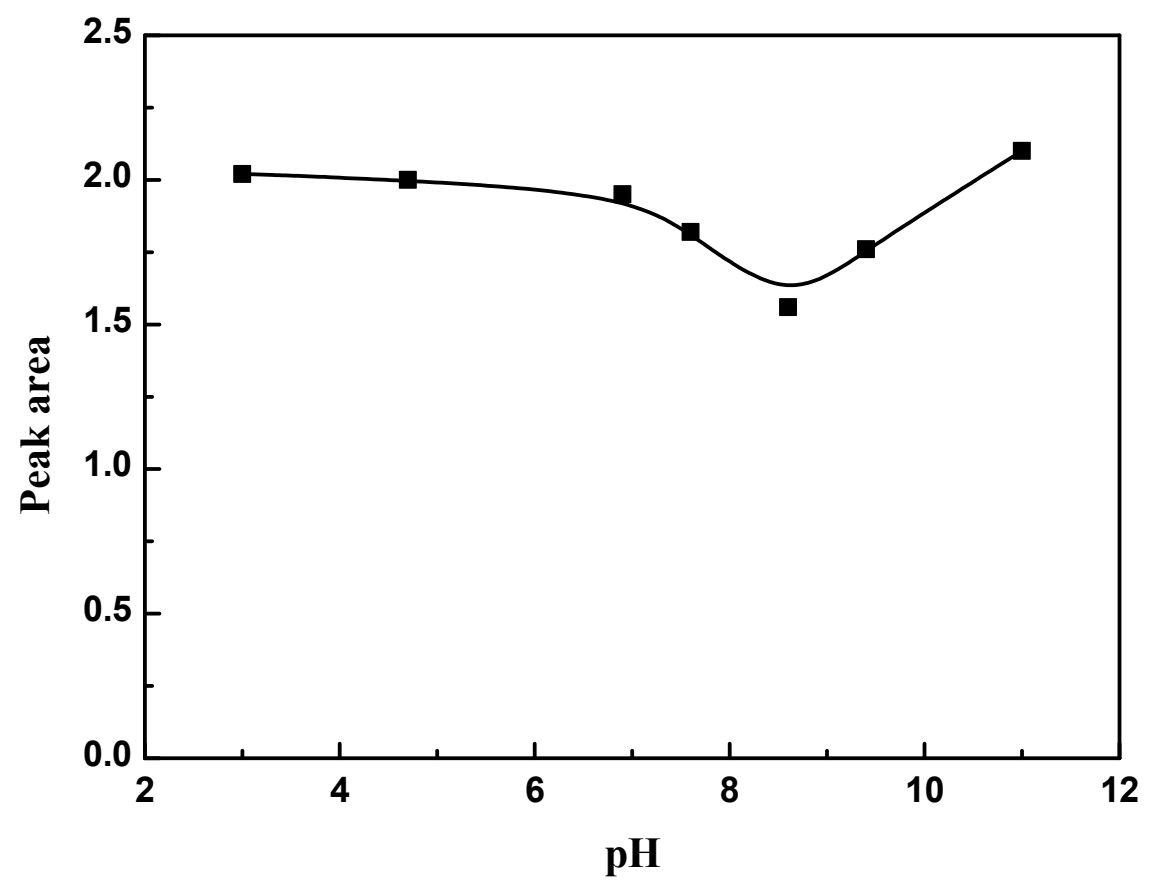

Figure 5. Effect of $\mathrm{pH}$ on the adsorption of Tyr amino acid on the GO's surface.

\subsection{Effect of Temperature}

The absorption spectra were recorded at different temperatures $\left(20,25,30,35\right.$, and $\left.40{ }^{\circ} \mathrm{C}\right)$, and each corresponding peak area was calculated. The data presented in Table 1 show that changing the temperature has no significant impact on the adsorption of Tyr. Therefore, the preferred temperature for the adsorption of Tyr onto the GO's surface is $25^{\circ} \mathrm{C}$.

Table 1. Effect of temperature on the adsorption of Tyr amino acid on GO.

\begin{tabular}{cc}
\hline Temperature $\left({ }^{\circ} \mathbf{C}\right)$ & Peak Area (A) \\
\hline 20.0 & 1.57 \\
25.0 & 1.56 \\
30.0 & 1.56 \\
35.0 & 1.58 \\
40.0 & 1.56 \\
\hline
\end{tabular}

\subsection{Effect of Shaking Time}

The effect of shaking time at $25^{\circ} \mathrm{C}$ was investigated (Figure 6), and the data obtained showed that the adsorption of Tyr on the GO's surface occurred immediately and stably up to 10 min without the necessity of shaking. For a shaking time greater than $10 \mathrm{~min}$, the area under peak was increased and this could be explained in terms of releasing Tyr from the GO's surface. 


\subsection{Adsorption of Tyr Amino Acid on GO Surface}

Under the optimum condition ( $1 \mathrm{~mL}$ of GO stock solution was added to $4 \times 10^{-4} \mathrm{M}$ of Tyr at $25^{\circ} \mathrm{C}$, with the $\mathrm{pH}$ adjusted to 8.4 ) of the variables previously discussed, comparative UV-vis spectra were recorded. The area under peak was calculated after $5 \mathrm{~min}$. As shown in Figure 7, the maximum absorbance of tyrosine appeared at $279 \mathrm{~nm}$ and after interaction of Tyr with the GO's surface, the peak was shifted to $274 \mathrm{~nm}$ (by a $5 \mathrm{~nm}$ decrease) and the peak of Tyr was carried on the GO peak. Also, the area under peak was decreased from 2.18 to 1.56 . These data indicated that Tyr was well-adsorbed on the surface of the GO.

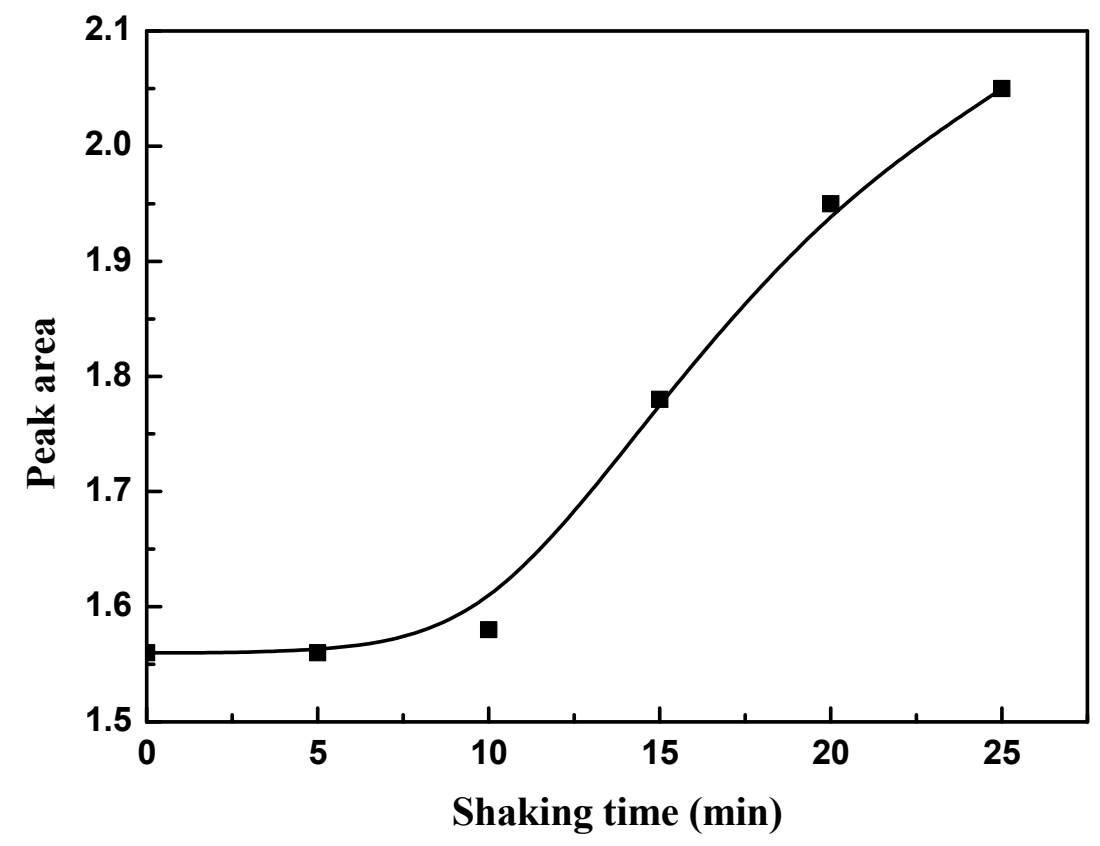

Figure 6. Effect of shaking time on the adsorption of Tyr amino acid on GO.

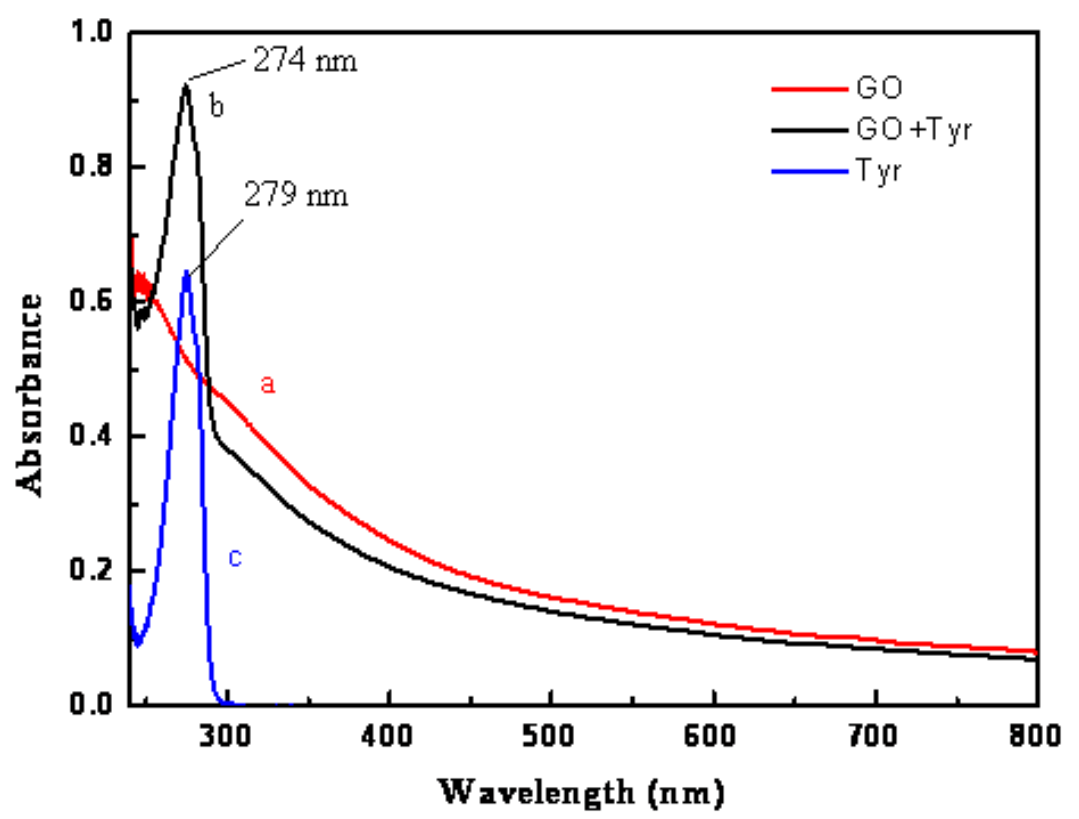

Figure 7. UV-visible absorption spectra for (a) GO; (b) GO in the presence of Tyr amino acid; and (c) Tyr amino acid. 


\section{Conclusions}

The adsorption of Tyr on the surface of GO was characterized and determined. The SEM analysis showed that the particle size of the GO used in this study ranged between 5.4 and $8.1 \mathrm{~nm}$. The UV-vis data and FT-IR indicated that the GO was on the nano-scale. The experimental data showed that Tyr was adsorbed rapidly at $25^{\circ} \mathrm{C}$ and that the suitable concentration of GO is $0.2 \mathrm{mg} / \mathrm{mL}$ for $8 \times 10^{-5} \mathrm{M}$ of Tyr amino acid at $\mathrm{pH}$ 8.4. The mechanism of adsorption of Tyr is mainly electrostatic attraction as it is clear from the study of the pH's effect. The maximum absorbance of tyrosine was obtained after its interaction with the GO's surface. The peak was shifted to $274 \mathrm{~nm}$ (by a $5 \mathrm{~nm}$ decrease), and the peak of Tyr overlapped the GO's peak. Also, the area under peak was decreased from 2.18 to 1.56. These data indicate that Tyr is well-adsorbed on the surface of GO.

Supplementary Materials: The following are available online at www.mdpi.com/1996-1944/11/1/68/s1, Figure S1: TEM image of single layer graphene (ACS Material-Graphene Factory), Figure S2: SEM image of single layer graphene (ACS Material-Graphene Factory), Figure S3: HRTEM image of single layer graphene (ACS Material-Graphene Factory), Figure S4: XRD patterns of single layer graphene (ACS Material-Graphene Factory), Figure S5: XPS patterns of single layer graphene (ACS Material-Graphene Factory), Figure S6: Raman spectrum of single layer graphene (ACS Material-Graphene Factory).

Acknowledgments: The authors gratefully acknowledge the Deanship of Scientific Research, Taibah University, for the support of this research work with project No. 7024/1436.

Author Contributions: Hossam M. Nassef designed the experiment, evaluated data's analysis and wrote the paper, Mohamed Hagar shared in the experimental part, wrote the paper. Zeiad Malek helped in experimental part. Abdelhameed M. Othman designed the experiment, evaluated data's analysis and wrote the paper.

Conflicts of Interest: The authors declare no conflict of interest.

\section{References}

1. Dreyer, D.R.; Park, S.; Bielawski, C.W.; Ruoff, R.S. The chemistry of graphene oxide. Chem. Soc. Rev. 2010, 39, 228-240. [CrossRef] [PubMed]

2. Zheng, J.; Di, C.-A.; Liu, Y.; Liu, H.; Guo, Y.; Du, C.; Wu, T.; Yu, G.; Zhu, D. High quality graphene with large flakes exfoliated by oleyl amine. Chem. Commun. 2010, 46, 5728-5730. [CrossRef] [PubMed]

3. Zhang, M.; Yin, B.-C.; Tan, W.; Ye, B.-C. A versatile graphene-based fluorescence "on/off" switch for multiplex detection of various targets. Biosens. Bioelectron. 2011, 26, 3260-3265. [CrossRef] [PubMed]

4. Chen, J.-L.; Yan, X.-P.; Meng, K.; Wang, S.-F. Graphene oxide based photoinduced charge transfer label-free near-infrared fluorescent biosensor for dopamine. Anal. Chem. 2011, 83, 8787-8793. [CrossRef] [PubMed]

5. Burress, J.W.; Gadipelli, S.; Ford, J.; Simmons, J.M.; Zhou, W.; Yildirim, T. Graphene oxide framework materials: Theoretical predictions and experimental results. Angew. Chem. Int. Ed. 2010, 49, 8902-8904. [CrossRef] [PubMed]

6. Liu, Z.; Robinson, J.T.; Sun, X.; Dai, H. PE Gylated nanographene oxide for delivery of water-insoluble cancer drugs. J. Am. Chem. Soc. 2008, 130, 10876-10877. [CrossRef] [PubMed]

7. Matko, V.; Koprivnikar, J. Quartz sensor for water absorption measurement in glass-fiber resins. IEEE Trans. Instrum. Meas. 1998, 47, 1159-1162. [CrossRef]

8. Matko, V.; Milanović, M. Temperature-compensated capacitance-frequency converter with high resolution. Sens. Actuators A Phys. 2014, 220, 262-269. [CrossRef]

9. Kim, J.; Cote, L.J.; Kim, F.; Huang, J. Visualizing graphene based sheets by fluorescence quenching microscopy. J. Am. Chem. Soc. 2009, 132, 260-267. [CrossRef] [PubMed]

10. Zhang, M.; Yin, B.-C.; Wang, X.-F.; Ye, B.-C. Interaction of peptides with graphene oxide and its application for real-time monitoring of protease activity. Chem. Commun. 2011, 47, 2399-2401. [CrossRef] [PubMed]

11. Pettit, L. Critical survey of formation constants of complexes of histidine, phenylalanine, tyrosine, L-DOPA and tryptophan. Pure Appl. Chem. 1984, 56, 247-292. [CrossRef]

12. White, B.R.; Stackhouse, B.T.; Holcombe, J.A. Magnetic $\gamma-\mathrm{Fe}_{2} \mathrm{O}_{3}$ nanoparticles coated with poly-l-cysteine for chelation of $\mathrm{As}(\mathrm{III}), \mathrm{Cu}(\mathrm{II}), \mathrm{Cd}(\mathrm{II}), \mathrm{Ni}(\mathrm{II}), \mathrm{Pb}(\mathrm{II})$ and $\mathrm{Zn}(\mathrm{II})$. J. Hazard. Mater. 2009, 161, 848-853. [CrossRef] [PubMed] 
13. Malachowski, L.; Stair, J.L.; Holcombe, J.A. Immobilized peptides/amino acids on solid supports for metal remediation. Pure Appl. Chem. 2004, 76, 777-787. [CrossRef]

14. Pacheco, P.H.; Smichowski, P.; Polla, G.; Martinez, L.D. Solid phase extraction of Co ions using L-tyrosine immobilized on multiwall carbon nanotubes. Talanta 2009, 79, 249-253. [CrossRef] [PubMed]

15. Othman, A.M.; Li, S.; Leblanc, R.M. Enhancing selectivity in spectrofluorimetric determination of tryptophan by using graphene oxide nanosheets. Anal. Chim. Acta 2013, 787, 226-232. [CrossRef] [PubMed]

16. Vacchi, I.A.; Spinato, C.; Raya, J.; Bianco, A.; Ménard-Moyon, C. Chemical reactivity of graphene oxide towards amines elucidated by solid-state NMR. Nanoscale 2016, 8, 13714-13721. [CrossRef] [PubMed]

17. Li, S.; Mulloor, J.J.; Wang, L.; Ji, Y.; Mulloor, C.J.; Micic, M.; Orbulescu, J.; Leblanc, R.M. Strong and selective adsorption of lysozyme on graphene oxide. ACS Appl. Mater. Interfaces 2014, 6, 5704-5712. [CrossRef] [PubMed]

18. Wang, Y.; Li, Z.; Wang, J.; Li, J.; Lin, Y. Graphene and graphene oxide: Biofunctionalization and applications in biotechnology. Trends Biotechnol. 2011, 29, 205-212. [CrossRef] [PubMed]

19. Venkatesha, N.; Poojar, P.; Ashwini, R.; Qurishi, Y.; Geethanath, S.; Srivastava, C. Ultrafine graphene oxide- $\mathrm{CoFe}_{2} \mathrm{O}_{4}$ nanoparticle composite as $T_{1}$ and $T_{2}$ contrast agent for magnetic resonance imaging. RSC Adv. 2016, 6, 17423-17429. [CrossRef]

20. Zhu, Y.; Murali, S.; Cai, W.; Li, X.; Suk, J.W.; Potts, J.R.; Ruoff, R.S. Graphene and graphene oxide: Synthesis, properties, and applications. Adv. Mater. 2010, 22, 3906-3924. [CrossRef] [PubMed]

21. Kumar, A.; Lee, C.H. Advances in Graphene Science; InTech: Rijeka, Croatia, 2013.

22. Chaiyakun, S.; Witit-Anun, N.; Nuntawong, N.; Chindaudom, P.; Oaew, S.; Kedkeaw, C.; Limsuwan, P. Preparation and characterization of graphene oxide nanosheets. Procedia Eng. 2012, 32, 759-764.

23. Advanced Chemical Supplier (ACS) Material LLC. Single Layer Graphene. Available online: https://www. acsmaterial.com/single-layer-graphene-graphene-factory-986.html (accessed on 30 April 2010).

(C) 2018 by the authors. Licensee MDPI, Basel, Switzerland. This article is an open access article distributed under the terms and conditions of the Creative Commons Attribution (CC BY) license (http://creativecommons.org/licenses/by/4.0/). 